\title{
Stressed and unstressed volumes of the peripheral vasculature
}

\author{
George L. Brengelmann, PhD
}

Received: 4 January 2018/Revised: 5 January 2018/ Accepted: 5 January 2018/Published online: 7 June 2018

(c) Canadian Anesthesiologists' Society 2018

\section{To the Editor,}

Gelman and Bigatello' ${ }^{1}$ state that "understanding the physiologic basis of such [goal-directed hemodynamic] therapy is a logical step towards its optimal use". But, besides ignoring some physiologists' criticisms of interpretations they espouse, ${ }^{2}$ they treat "stressed" and "un-stressed" volumes as separate entities that move according to a vague scheme illustrated in their Fig. 1. Like other hollow elastic structures (e.g., cardiac ventricles, thorax), the vasculature has a "rest volume". Bled out to the point that mean circulatory filling pressure (Pms) - i.e., the pressure throughout the vasculature with the heart stopped - is zero, the vasculature still holds a residual volume (Vr). Adding an increment of volume (Vs) to the vascular container to increase the total volume $(\mathrm{Vt})$ to $\mathrm{Vs}+\mathrm{Vr}$ elevates Pms above zero in proportion to total compliance. The components of the new $\mathrm{Vt}$ are not somehow separate. The stress is in the elastic walls; the pressure they exert is felt throughout the container. In essence, Vs is like the last straw misrepresented as the one that broke the camel's back.

When flow is forced through the peripheral vasculature, initially at zero flow and some positive Pms, pressure differences develop along vascular segments in proportion to their viscous resistance, stretching those where pressure

This letter is accompanied by a reply. Please see Can J Anesth 2018; 65: this issue.

G. L. Brengelmann, PhD (ه)

Department of Physiology and Biophysics, University of

Washington, Seattle, WA, USA

e-mail: brengelm@uw.edu rises above Pms, thereby increasing the fraction of the total blood volume within them. Correspondingly less is held within downstream segments, now at pressures below Pms. $^{2,3}$ The greater the flow, the lower the pressure at the entry to the right atrium. ${ }^{4}$

Flow-dependent redistribution of volume becomes a problem when volume within the large collecting veins falls to the point that their distending pressure falls to zero. Untethered to surrounding tissues 5 and at the lowest distending pressures of the vascular circuit, these are the first segments to lose distending pressure, consequently tending to collapse and impede flow as observed by Guyton. ${ }^{4}$

Volume and pressure profiles can change counterintuitively. For example, constriction of muscular splanchnic veins could result in increased pressure within upstream compliant post-capillary venules, reallocating volume upstream, not to downstream segments at risk of collapse. A more comprehensive treatment of dynamic volume redistribution has been reviewed by Rowell. ${ }^{3}$

How clinical interventions alter these profiles needs to be understood in terms of what happens to the various resistances and compliances of affected vascular segments and their effects on the distribution of flow and volume among the organ vasculatures, not mysterious shifting about of unstressed and stressed bits.

Acknowledgement I gratefully acknowledge the secretarial and editorial support of the University of Washington Department of Physiology and Biophysics. 
Conflicts of interest None declared.

Editorial responsibility This submission was handled by Dr. Hilary P. Grocott, Editor-in-Chief, Canadian Journal of Anesthesia.

\section{References}

1. Gelman S, Bigatello L. The physiologic basis for goal-directed hemodynamic and fluid therapy: the pivotal role of the venous circulation. Can J Anesth 2018. DOI: https://doi.org/10.1007/ s12630-017-1045-3.

2. Brengelmann GL. A critical analysis of the view that right atrial pressure determines venous return. J Appl Physiol 1985; 2003(94): 849-59.

3. Rowell LB. Human Circulation Regulation During Physical Stress. NY: Oxford University Press; 1986.

4. Guyton AC, Lindsey AW, Abernathy B, Richardson T. Venous return at various right atrial pressures and the normal venous return curve. Am J Physiol 1957; 189: 609-15.

5. Rothe CF. Reflex control of veins and vascular capacitance. Physiol Rev 1983; 63: 1281-342. 